\title{
COMPARATIVE ASSESSMENT OF PM MATERIAL FOR TURBINE DISKS
}

MTU MOTOREN - UND TURBINEN-UNION MONCHEN GMBH M.A.I. MAYBACH MERCEDES-BENZ

\author{
W. Betz \\ B. Borchert \\ W. Track
}

An assessment of the properties of the three turbine disk alloys Waspaloy, IN 718 and MV 1460 (PM Udimet 700 type) shows that the PM material is preferably to be used for higher temperature applications and at lower stresses (strains). Cyclic spin tests however do not show significant differences in 1 ife on the test disks for all materials at room temperature.

A problem for utilizing the full potential of the PM material is cleanliness of the powder, but the higher attainable minimum properties and large expectable costs savings predict, that there will be extensive use of PM material in gas turbine engines in the near future. 


\section{PROBLEM}

MTU Müchen have already been engaged in the field of powder metallurgy for turbine disks for nearly a decade. Some of this research has already been pub1 ished elsewhere (1) (2).

The following points characterize the main potential of powder metallurgy using hot isostatic pressing (HIP)

- Improved homogeneity of the structure in 211 its characteristics and consequently:

- Lower scatter of the properties

- Higher useful minimum values

- Better control over the structure

- Use of alloys without regard to castability and forgeability, thus permitting better properties to be reached than before.

- Lower cost of manufacture of components, thanks to savings in material as a result of manufacture to near-net shape.

It is the purpose of this contribution to compare some of the properties which are important for the design of turbine disks, as found on the one hand in Waspaloy and IN 718, the forged alloys currently in usc, and as determined in a PM material (type Udimet 700) on the other.

The PM material in question was in hot isostatic pressed condition. In the following, the material has been given the MTU designation MV 1460, and this covers the various trade designations of $U 700$, APK1, Astraloy, etc. The properties shown correspond to an optimal heat-treated condition for larger material cross-sections. The conventionally forged materials were in their usual commercial condition. Some of them have been discussed in greater detail in earlier works (3) (4).

\section{RESULTS AND THEIR EVALUATION}

The ultimate tensile strength of the PM material MV 1460 is clearly superior to that of the two conventional materials, especially at elevated temperatures (Fig. 1). In contrast, IN 718 has the 
best yield strength Rp 0.2 at lower and intermediate temperatures. At elevated temperatures, the PM material once again shows its superiority. Waspaloy has the lowest values in all temperature ranges.

With the PM material MV 1460 the elongation and reduction in area always 1 ie between 15 and $30 \%$. They are thus comparable with or higher than the values for the forged materials. The scatter range of the static strengths of conventional materials are roughly $+5 \%$, whereas a scatter range of less than $\pm 1 \%$ cān be attained for MV 1460 .

Certain sections of modern turbine disks have to withstand such high temperatures that the creep behaviour, e.g. the creep rupture strength, must also be taken into consideration. In this connection, in Fig. 2 it can be seen that at a test temperature of $730^{\circ} \mathrm{C}$, the life of MV 1460 lies in the uppermost range of the wide scatter bands for IN 718 or Waspaloy. Here, the material MV 1460's particular suitability for high-temperature service becomes apparent.

By far the most important material characteristics for disk applications are the dynamic strengths. Figs. 3 and 4 show the relationships in a stress-controlled test at room temperature and $600^{\circ} \mathrm{C}$. As expected, at room temperature the very wide scatter band of the Waspaloy values is the lowest. The scatter band for IN 718 and MV 1460 at room temperature pretty much coincide. However, Ii 718 can be used to somewhat higher stresses.

There is a shift in the relationships at $6000 \mathrm{C}$ : Waspaloy indeed again shows the lowest scatter, but the scatter of MV 1460 is clearly above it, and that of IN 718 has slipped to or below its bottom line.

No turbine disk today can go without permitting enforced plastic strain to occur at certain points, e.g. in notches through thermal stresses. Information on the behaviour of a material in such a situation is obtained by means of strain-controlled fatigue tests. The test values for our three comparative materials at room temperature are summarized in Fig. 5. In this case, Waspaloy appears to be slightly superior under high strain. IN 718 and MV 1460 follow practically the same curve. The course of the curve under the highest strains does 
not conform to prevailing theories. This could be simply attributable to the test conditions, and for this reason this phenomenon is not gone into in detail here.

The relevance of these comparative statements, gained from specimen values, can be checked by comparing the results of spin tests on 1 arge $(380 \mathrm{~mm}$ dia) and small ( $123 \mathrm{~mm}$ dia) disks made from the three materials in question. The lives of such disks up to incipient cracking (approx. 0.5 to $1.0 \mathrm{~mm}$ crack length) are plotted in Fig. 6 against the theoretical elastic stress amplitudes at critical points on the disks, resulting from the speed and geometry. Very good correspondence with the situation with strain-controlled specimens at lesser strain amplitudes is recognizable: Waspaloy continues its tendency as the weakest material, whereas IN 718 and MV 1460 fall roughly into the same scatter range. In general, the differences must be regarded as small. The lives should differ more clearly in experiments conducted at higher temperatures. However, these tests have not yet been completed.

A peculiarity of powder metallurgy materials is the clear dependency of the number of load cycles attainable in the fatigue test on the material's freedom from defects. More details on this are to be found elsewhere (5), but the essentials should be repeated here:

The results of stress-controlled LCF tests to date correspond to today's state of the art in manufacture. In contrast, if we look at earlier tests or tests using deliberately impure material (6), we have an appreciably wider scatter (Fig. 7), which however can be represented considerably more clearly on the basis of fracture-mechanical considerations (Fig. 8). In this case, each foreign particle (dia $2 a$ ) responsible for triggering the crack was regarded as an open crack, and the relevant stress intensity $(k \sim \sigma \sqrt{a})$ was plotted over the life. This picture permits a safe life of components to be assessed from the defect-content of the powder and the probability of the foreign particles being in a certain location, as well as from the prevailing stress. Alternatively, for a given load and required life, a statement $c$ an be made concerning the quality of material required. 
The same principle of consideration can also be applied to conventional forged materials, but in this case it is appreciably more difficult to describe the defects which occur clearly and to predict their effects. In any case, it must be borne in mind that NDT methods available today can only cater for defects larger than $0.4 \mathrm{~mm}$. In Fig. 8 this corresponds to a $\mathrm{K}-\mathrm{value}$ of about $30 \mathrm{MNm}^{-3 / 2}$ under usual loads.

From Fig. 7, minimum diameters for harmful defects of approx. 25 and $60 \mu \mathrm{m}$ result for stress-controlled loads of about $1000 \mathrm{MNm}-3 / 2$, depending on the position of the defect (inner/edge position). Defects smaller than this are harmless.

When the loads are strain controlled, the conditions may possibly be more favourable. Here, purposely introduced impurities of up to $100 \mu \mathrm{m}$ diameter have virtually no influence on the load cycles attainable (Fig. 8).

Finally, let us look at the costs aspect:

Powder metallurgy's greatest advantage lies in the considerable savings in material, afforded by the manufacture of near-net shapes. This is accompanied by the possibie improvement in the properties of the material. which make themselves felt in lower operating costs (efficiency, flying weight). These costs advantages are offset somewhat by the rather more expensive method of manufacture. As a whole, we expect the following approximate costs relationship between the different methods of manufacture of turbine disks, where the geometry and suitability for testing of a component are essentially included in the result:

Conventional forging

Hot isostatic pressing $0.7-1.2$
HIP plus subsequent forg. $1.5-3$

HIP plus isothermal forg. $3-5$

\section{CONCLUSIONS}

It can be said that the powder metallurgy material MV 1460 is the equal or better of the materials previously used, IN 718 and Waspaloy, for turbine disks at high temperatures. At low temperatures 
IN 718 may have the best properties. However, this advantage has not yet been verified in spin tests on test disks.

The serviceability of PM materials very much depends on the achievable cleanliness of the powder during manufacture. This demand for purity will indeed have its effects with regard to costs in PM technology, but the costs advantages to be gained from the possible savings in material (especially with the increasing shortage of raw materials) afforded by the near-net shape of the component lead one to expect the rapidly increasing use of these materials.

\section{REFERENCES}

(1) W. Betz et al.

"Investigations for Manufacturing Turbine Disks of Ni-Base Superalloys by Powder Metallurgical Methods"

AGARD Conference Proceedings No. 200,1975

(2) W. Betz, W. Track, W. Keinath

"Manufacture of PM-Turbine Disks for Aero Engines by the HIP Single Stage Process"

Preprints to 5 th. European Symposium on Powder Metallurgy Vol. 1, S. 13-18; Stockholm 1978

(3) B. Borchert, W. Betz

"Verhalten von Turbinenwerkstoffen unter Low Cycle Fatigue"

Research Report to Eurocop-COST, $50 \mathrm{D} 3 / 3$ MTU-München 1977

(4) B. Borchert

"Low Cycle Fatigue and Service Life of Engine Rotor Disks"

in "High Temperature Alloys for Gas Turbines" by 1978 Applied Science Publishers Ltd.

Ripple Road, Barking, Essex, England 
(5) W. Betz, W. Track

"Structural Defects Governing the Potential Use and Limitations PM-Ni-Base Materials" 109th. AIME Annual Meeting 1980 (to be pub1 ished).

(6) F.A. Thompson, C.P. Cutler, R.J. Siddall

"The Influence of Inclusions on the Low Cycle Fatigue Properties of the Ni-Based Superalloy APK 1 ..."

Henry Wiggin Technical Report TR 31841979

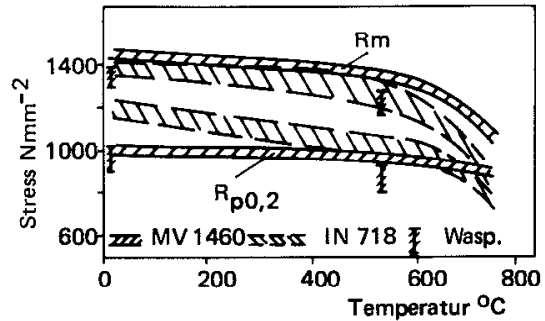

Fig 1 Ultimate tensile and yield strengths

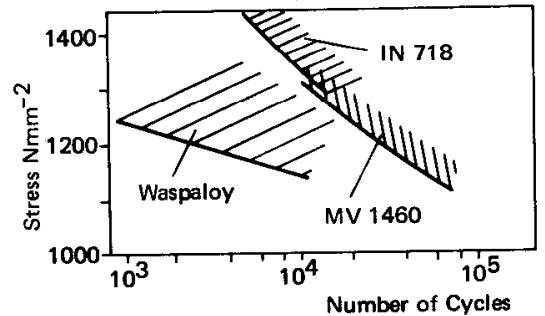

Fig. 3 LCF behaviour (stress controlled, $20^{\circ} \mathrm{C}$ )

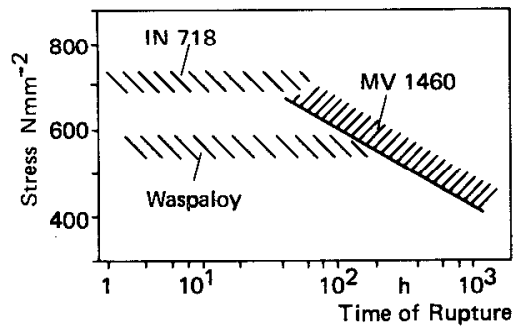

Fig. 2 Stress rupture properties at $730^{\circ} \mathrm{C}$

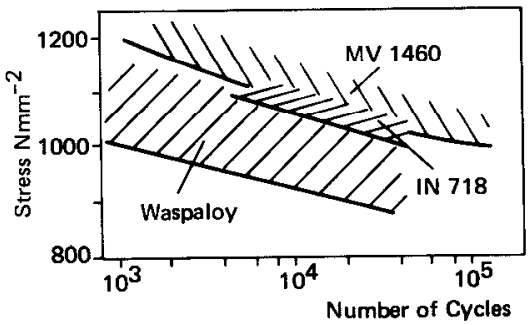

Fig. 4 LCF behaviour (stress controlled, $600^{\circ} \mathrm{C}$ ) 


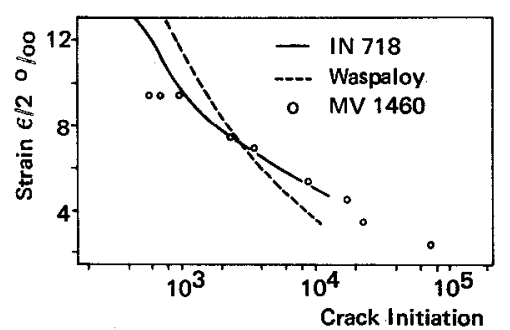

Fig 5 LCF behaviour (strain controlled $20^{\circ} \mathrm{C}$ )

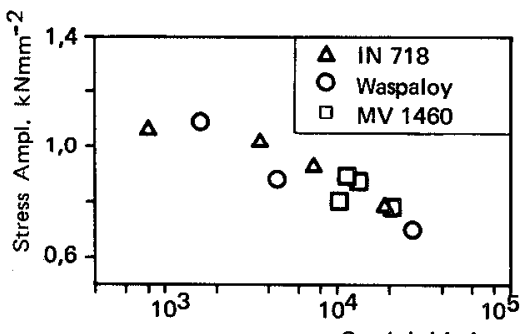

Crack Initiation

Fig. 6 Cyclic life of disks in spin tests $\left(20^{\circ} \mathrm{C}\right)$

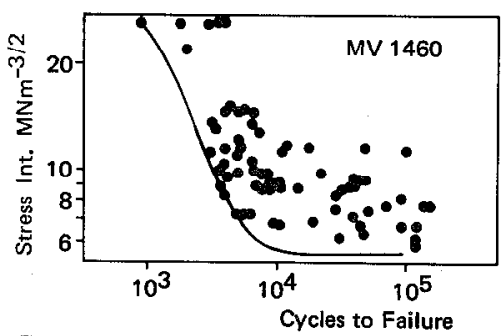

Fig. 8 LCF life in relation to stress intensity on defects $\left(600^{\circ} \mathrm{C}\right)$

Fig. 7 LCF scatter for PM-material with defects $\left(600^{\circ} \mathrm{C}\right)$ 